\title{
Design and Analysis of Single Stack AFPM Machines with and without Air Gap between Rotor and Magnetic Poles
}

\author{
Abdul Majeed Shaikh ${ }^{1}$, Umar Abdul Majeed ${ }^{1}$, Muhammad Fawad Shaikh ${ }^{1}$, Sheeraz Ahmed ${ }^{1}$, and Muhammad Bux ${ }^{1}$ \\ ${ }^{I}$ Department of Electrical Engineering, Sukkur IBA University, Sukkur, Sindh, Pakistan \\ Correspondence Author: Muhammad Fawad Shaikh (muhammadfawad@iba-suk.edu.pk)
}

Received December 31, 2021; Revised January 28, 2022; Accepted February 22, 2022

\begin{abstract}
Permanent Magnet (PM) machines are widely used due to their low cost, lightweight, small size, and better operating efficiency. Axial Flux Permanent Magnet (AFPM) machines are famous for low-speed applications with good efficiency. These machines are used in elevators, wind power production, and electric vehicles. In this paper, two single stack AFPM machines with air gap and without air gap are designed using the Diameter to Length $\left(D^{2} L\right)$ method. Various parameters are calculated with this approach. Power, back emf, coil flux, and flux density are the parameters that are analyzed. Moreover, it was observed that power fluctuates in single stack AFPM machines without air gap and power quality issue is taken into account. Apart from this, balance voltages are observed in both machines, while magnetic flux density decreases in machines with air gaps and enhances without air gaps. 'SolidWorks' is used for designing purposes and then the JMAG designer tool is also used to perform analysis using the Finite Element Method (FEM).
\end{abstract}

Index Terms: Power, Back EMF, Coil Flux, Magnetic Flux Density, Air Gap, Permanent Magnet.

\section{INTRODUCTION}

Electrical Machines are playing a crucial role in this era and technology has progressed a lot [1] and [2]. For decades the need for machines with enhanced performance has been increased [3]. The performance of machines is mainly associated with the industrial sector and this has become a major concern for developing countries [4] and [5]. The design of electrical machines has drawn a lot of attention from researchers to design more efficient machines. Different materials are used for designing electrical machines and one of them is a permanent magnet [6] and [7]. The numerous advantages of permanent magnet machines like small size, low weight, high power, and high efficiency are increasing day to day. Permanent Magnet machines do not involve any other technique for the purpose of field excitation [8-13]. Permanent magnets lie in two categories, i.e., rare earth materials and non-rare earth materials. As rare earth materials are quite expensive when compared with non-rare earth materials. Non-rare materials are preferred for industrial applications [14]. The emerging Permanent Magnet (PM) machines are widely utilized currently in wind and direct drive train applications [15]. Accordingly, the characteristics of PM machines rely on the number of poles, stator slots, and magnet shape [16].

As far as wind applications are concerned, the permanentmagnet machine is least disruptive, highly powerful and seems to have high durability, and became one of the most significant items of machinery, however, the efficiency of this machine is $94 \%$ with zero core losses and less amount of eddy currents [17].

Flux is considered as one of the important parameters used in machines and with this PM machines are categorized as axial flux, transverse flux, and radial flux machines. However, Transverse flux type machines are not suitable for wind energy applications. Adding further, radial flux machines are simple in structure and easy to operate and according to design methodology, these machines are further classified into the surface mount, buried type, and inset type [17-19]. According to the literature, many studies are taken into account for radial flux machines; with inner and outer rotor types machines having different power with different air gaps and also a different number of turns per phase [20] and [21]. But our study is mainly focused on the analysis of a single stack Axial Flux Permanent Magnet (AFPM) machine with air gap and without air gap between magnetic poles with identical parameters for both machines.

In this paper, two models of single stack AFPM machine for design is discussed in Section II, methods and material used are conferred in Section III, design of the proposed models on solid works and JMAG is elaborated in Section IV, while in Section V results and analysis are expressed in detail, and Section VI concludes this research work. 
II. MODELS FOR DESIGNING OF SINGLE STACK AFPM MACHINE

Figure 1(a) shows the rotor design without an air gap between the magnetic poles with two outer rotors and one inner stator, core is not considered. Meanwhile, Figure 1(b) shows the rotor design with an air gap between the magnetic poles with two outer rotors and one inner stator, core is not considered. It is important to mention that coreless machines are considered in order to avoid core losses.
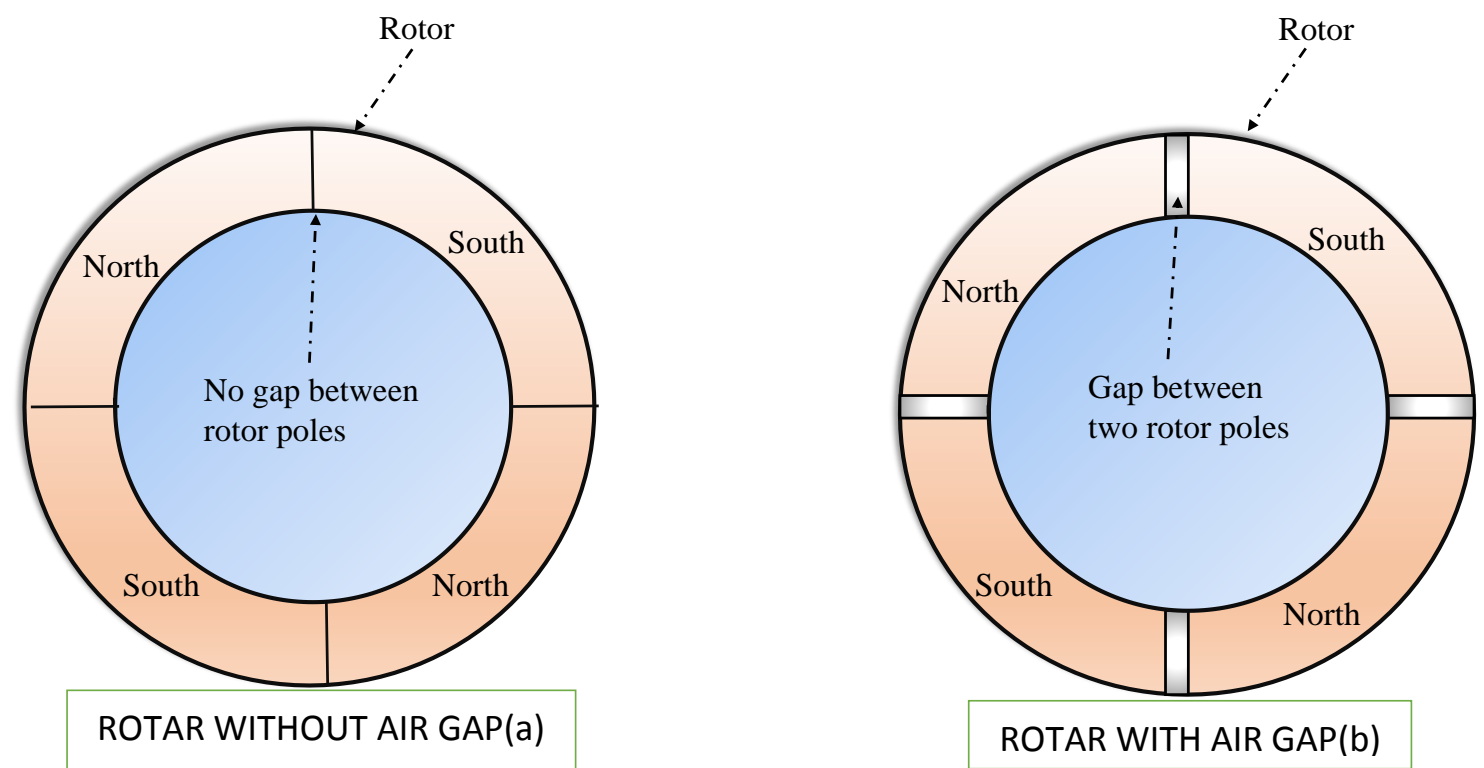

Figure 1: (a) Rotor without Air Gap; (b) Rotor with Air Gap

\section{MODELS FOR DESIGNING OF SINGLE STACK AFPM MACHINE}

The Diameter to Length $\left(\mathrm{D}^{2} \mathrm{~L}\right)$ method is used in this study. It is a mathematical method used in the design of electrical machines. Figure 2 shows the design methodology required for the $\mathrm{D}^{2} \mathrm{~L}$ method. In this paper, each model has mainly three parts rotor core, magnetic poles, and stator coils. The copper material is assigned to the stator coils, permanent magnet material named neodymium-iron born $\mathrm{NdFeB}$ permanent magnet grade 'TDK NEOREC 35SH' is applied to the magnetic poles of the rotor. Steel ' $50 \mathrm{H} 1000$ ' material is applied to the core of the rotor.

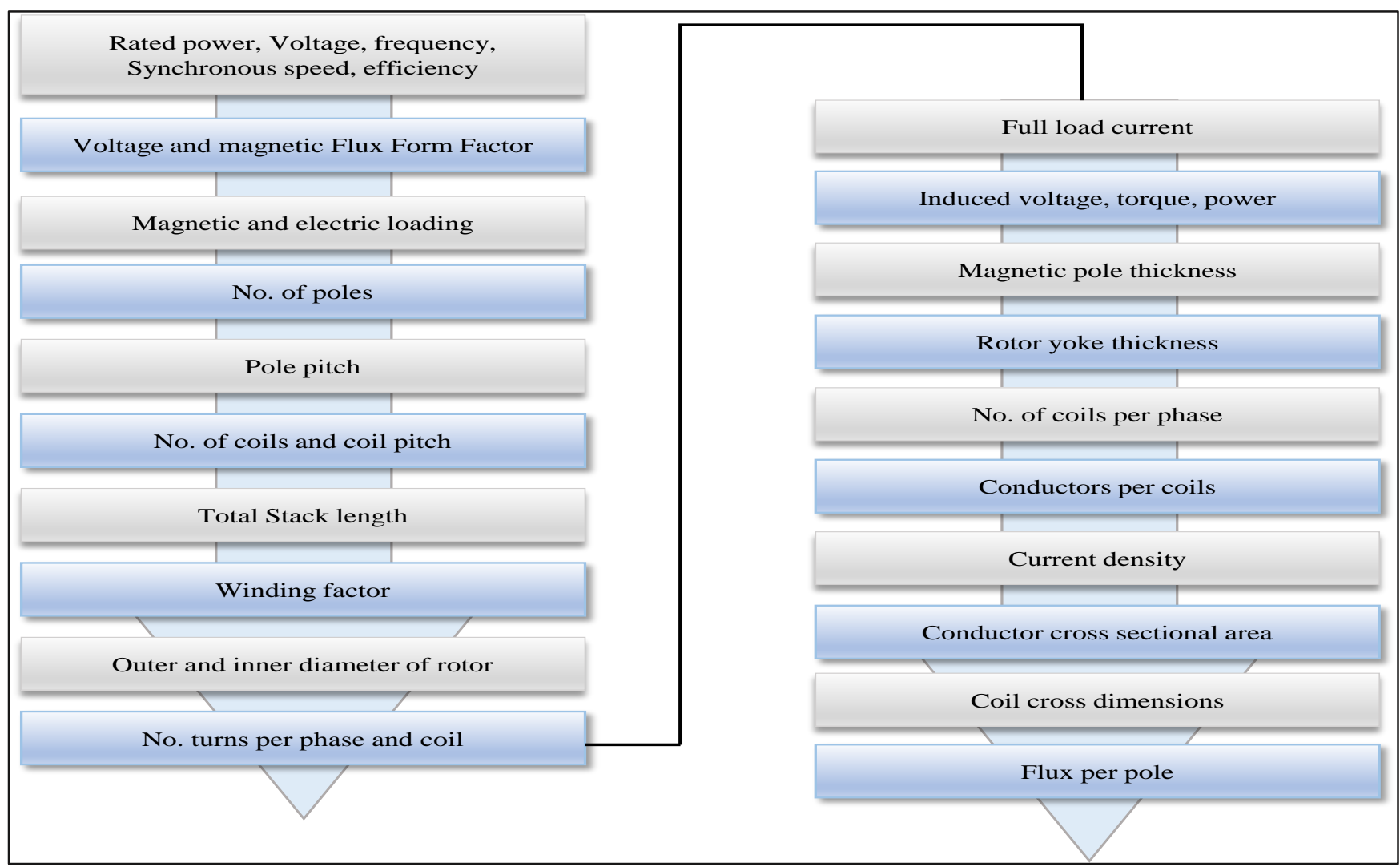

Figure 2: Design Process of AFPM Machine [22] 
For design process of AFPM machines as mentioned in Figure 2, it is grouped into two stages. The first stage for designing a machine is to determine the initial parameters, like power, voltage, frequency, and synchronous speed. The identical parameters for both proposed machines with air gap and without air gap are mentioned in Table 1.

Table 1: Initial Design Parameters of Machine with Air Gap and

\begin{tabular}{|l|c|c|}
\multicolumn{2}{c}{ without Air Gap } \\
\multicolumn{1}{|c|}{ Parameters } & Unit & Value \\
\hline Output Power & Watt & 3000 \\
\hline Phase Back EMF & Volt & 180 \\
\hline Frequency & Hertz & 50 \\
\hline Synchronous Speed & RPM & 375 \\
\hline
\end{tabular}

As the first stage was to determine the initial design parameter for both machines which are considered in this research, now in the second stage $\mathrm{D}^{2} \mathrm{~L}$ method is used to improve the procedure mentioned in Figure 2. The most important equations used for the parameters considered in this research are discussed. Flux form factor $(\mathcal{E})$ can be computed by Eq. (1). Voltage form factor $(\sigma f)$ is calculated using Eq. (3). $E_{f}$ is the back EMF and $\mathrm{V}$ signifying the phase voltages used in Eq. (3) [22].

$$
\begin{gathered}
\mathcal{E}=\frac{4}{\pi} \sin \left(\frac{B_{m g}}{B_{r}} \cdot \frac{\pi}{2}\right) \\
\sigma \mathrm{f}=\frac{E_{f}}{V}
\end{gathered}
$$

Here in Eq. (1) $B_{m g}$ and $B_{r}$ represent magnetic and residual flux density. While the number of poles is determined by Eq. (3) [23].

$$
\mathrm{P}=\frac{60 f}{N_{S}}
$$

In Eq. (2) P, f and $\mathrm{N}_{\mathrm{s}}$ show no. of poles, frequency, and synchronous speed consecutively.

The inner pole pitch $\tau_{\mathrm{i}, \text {, outer pole pitch }} \tau_{\mathrm{o}}$, inner stator coil pitch $\left(\zeta_{\mathrm{i}}\right)$, outer stator coil pitch $\left(\zeta_{\mathrm{o}}\right)$ and the total axial length of the machine (L) are computed by Eq. (4) to Eq. (8) respectively [22-24].

$$
\begin{aligned}
& \tau_{\mathrm{i}}=\frac{\pi \mathrm{Di}}{2 p} \\
& \tau_{\mathrm{o}}=\frac{\pi \mathrm{Do}}{2 p} \\
& \zeta_{\mathrm{i}}=\frac{\pi \mathrm{Di}}{s} \\
& \zeta_{\mathrm{o}}=\frac{\pi \mathrm{Do}}{s} \\
& \mathrm{~L}=2_{\mathrm{J}}\left(\mathrm{h}_{\mathrm{M}}+\mathrm{g}+\mathrm{h}_{\mathrm{Y}}\right)+\mathrm{h}_{\mathrm{c}}
\end{aligned}
$$

In Eq. (8), j, hM, g, hy, hc, shows the number of stacks, pole thickness, air gap, rotor yoke thickness, and stator coil thickness consecutively. Winding factor $\left(\mathrm{K}_{\mathrm{w} 1}\right)$ is given by Eq. (9) [25]. The outer diameter of the rotor $D_{0}$ is calculated using Eq. (10) [26].

$$
\begin{gathered}
\mathrm{K}_{\mathrm{w} 1}=\mathrm{K}_{\mathrm{d} * \mathrm{~K}_{\mathrm{p}}} \\
\mathrm{D}_{0}=\sqrt[3]{\left(\sigma \mathrm{f} \varepsilon p_{r}\right) /\left(\pi^{2} K_{D} B_{m g} A_{m} K_{w 1} n_{s} \eta\right)}
\end{gathered}
$$

\section{Where;}

$p_{r}$ represents rated power to be measured in $\mathrm{kW}$,

$\mathrm{K}_{\mathrm{D}}$ is the machine size constant,

$A_{m}$ is the electrical loading,

$\mathrm{K}_{\mathrm{w} 1}$ is the winding factor, and

$\eta$ represents the efficiency of the machines.

The machine size constant can be determined by Eq. (11), in which $\lambda$ represents the ratio of the inner and outer diameters of the rotor [27]. The inner diameter of rotor $D_{i}$ can be computed by Eq. (12) [28].

$$
\begin{gathered}
K_{D}=\frac{\left[(1+\lambda)\left(1-\lambda^{2}\right)\right]}{8} \\
D_{i}=\lambda D_{o}
\end{gathered}
$$

From these equations, the calculated identical parameters for both the Single Stack AFPM machines with air gap and without air gap are achieved and these calculated values are rotor and stator inner and outer diameter are yoke thickness, air gap, coil thickness, stack length, no. of poles, stator coils and no. of turns per coil. These parameters along with values are mentioned in Table 2. Only one parameter is not considered for single stack AFPM machine from Table 2 and that is the air gap.

Table 2: Calculated Design Parameters of Machine with Air Gap and without Air Gap

\begin{tabular}{|l|c|}
\multicolumn{1}{|c|}{ Parameter } & Value \\
\hline Rotor Outer Diameter & $372 \mathrm{~mm}$ \\
\hline Rotor Inner Diameter & $249 \mathrm{~mm}$ \\
\hline Stator Outer Diameter & $413 \mathrm{~mm}$ \\
\hline Stator Inner Diameter & $272.58 \mathrm{~mm}$ \\
\hline Rotor Yoke Thickness & $9.2 \mathrm{~mm}$ \\
\hline Air Gap & $1.5 \mathrm{~mm}$ \\
\hline Coil Thickness & $22 \mathrm{~mm}$ \\
\hline Total Stack Length & $57.9 \mathrm{~mm}$ \\
\hline No: of Poles per Rotor Disk & 16 \\
\hline Stator Coils & 12 \\
\hline No: of Turns per Coil & 112 \\
\hline
\end{tabular}

\section{JMAG DESIGN OF SINGLE STACK AFPM MACHINE WITH AND WITHOUT AIR GAP}

The designing process of both single-stack machines in JMAG designer is discussed in detail in the flow chart, which is mentioned in Figure (3). All of the stated steps in Figure (3) are used by the JMAG designer for simulation analysis. It takes time to simulate the whole model because as much as we discretize the model more will be the accuracy and fewer will be errors. In the end, once the simulation is completed the results and graph icons will be displayed below the mesh tab.

Through the rotor designs, as shown in Figure 1(a) and Figure 1(b), the axial flux PM machine has been designed by using 3D SolidWorks. After that these files are imported into JMAG designer to perform FEM analysis. AFPM single stack consists of one stator and two outer rotors, magnetic poles are placed on the rotor core which is facing towards the stator side. The stator is constructed as coreless and it has twelve stator coils. The rotor has two cores and sixteen magnetic poles that are placed on each core of the 
rotor. The design of single-stack AFPM is shown in Figure 5. Whereas, Figure 4(a) and Figure 4(b) show the construction of rotor without air gap and with air gap consecutive.

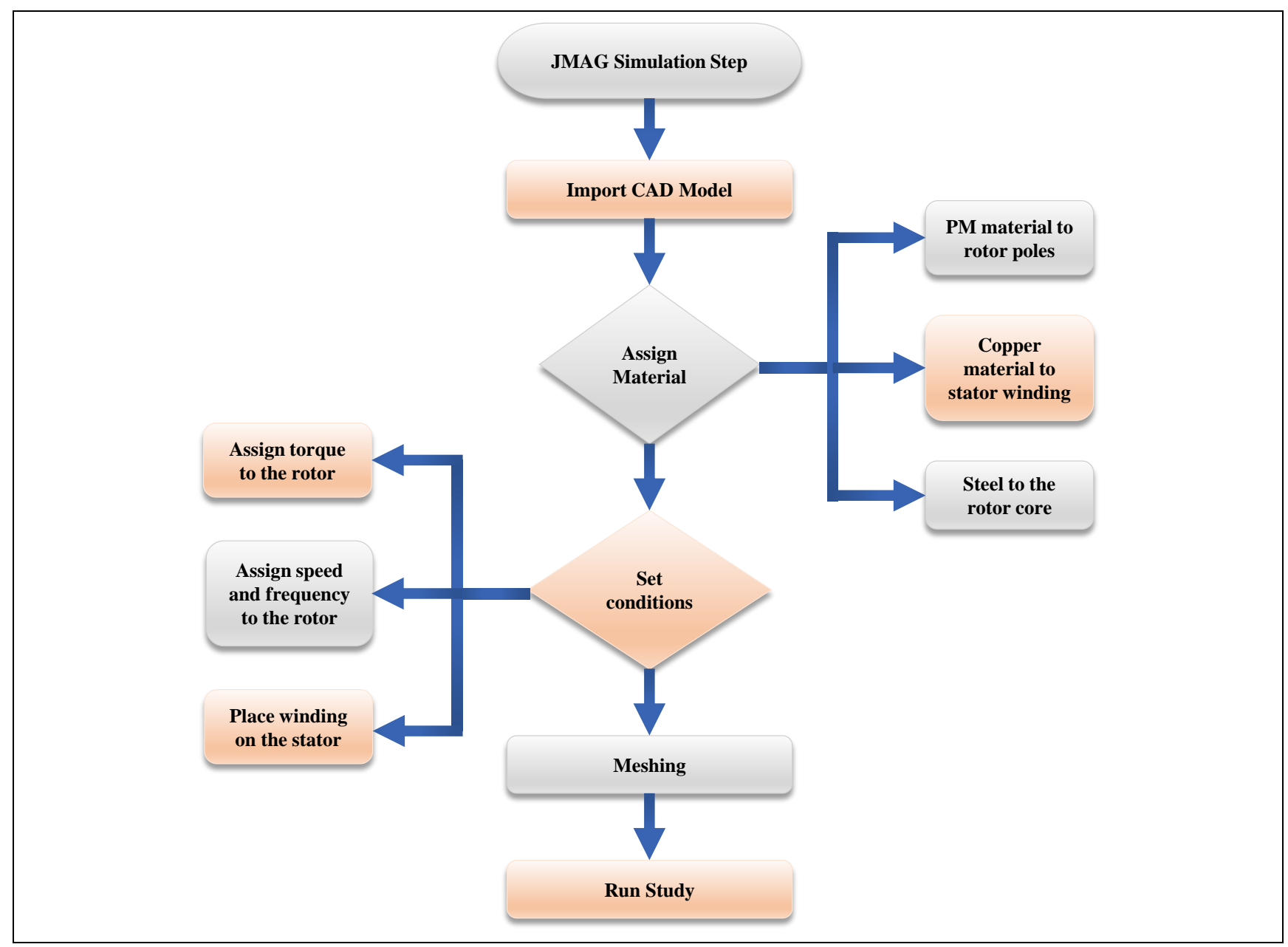

Figure 3: JMAG Designing Process

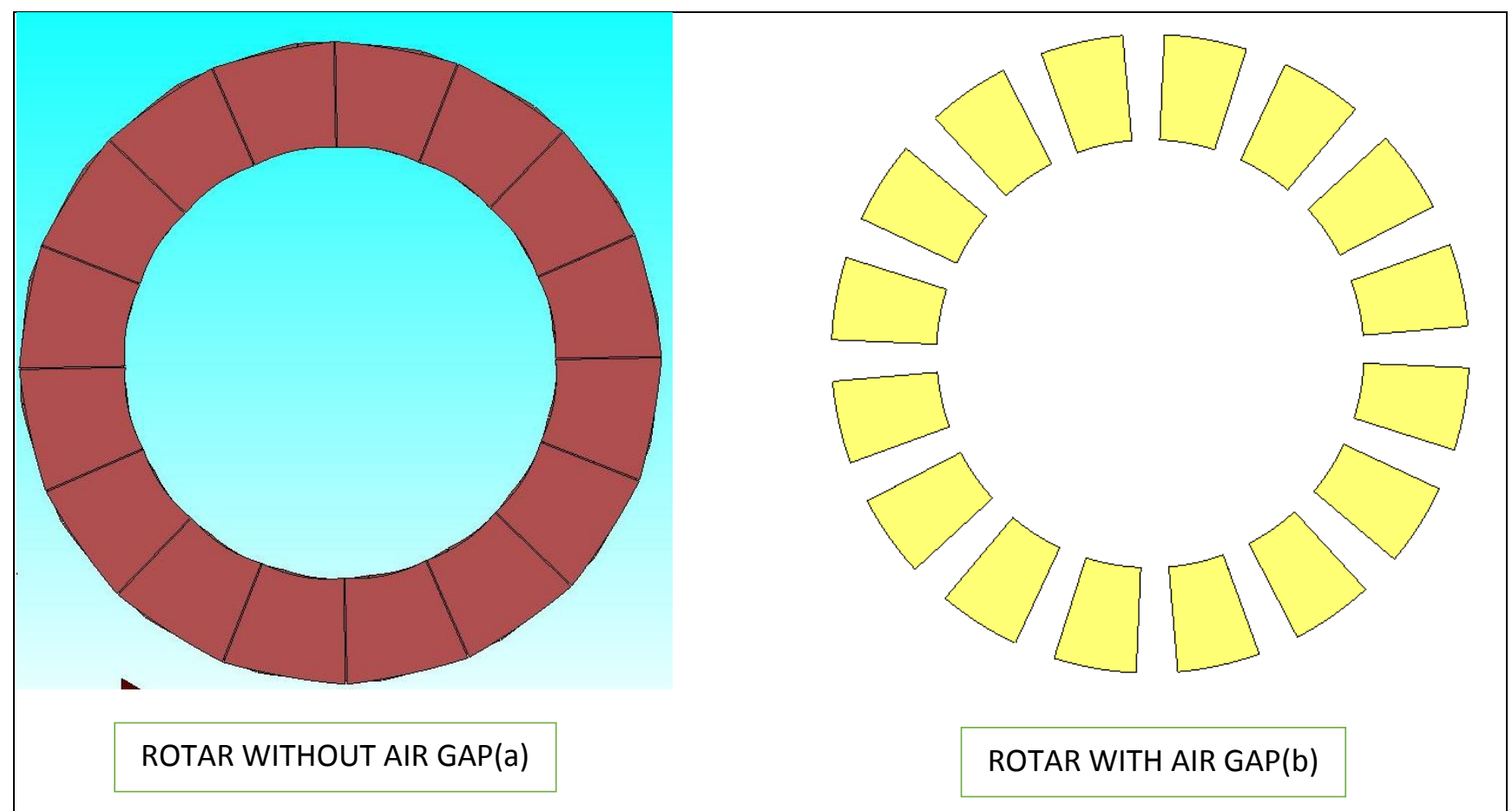

Figure 4: (a) Rotor without Air Gap; (b) Rotor with Air Gap 


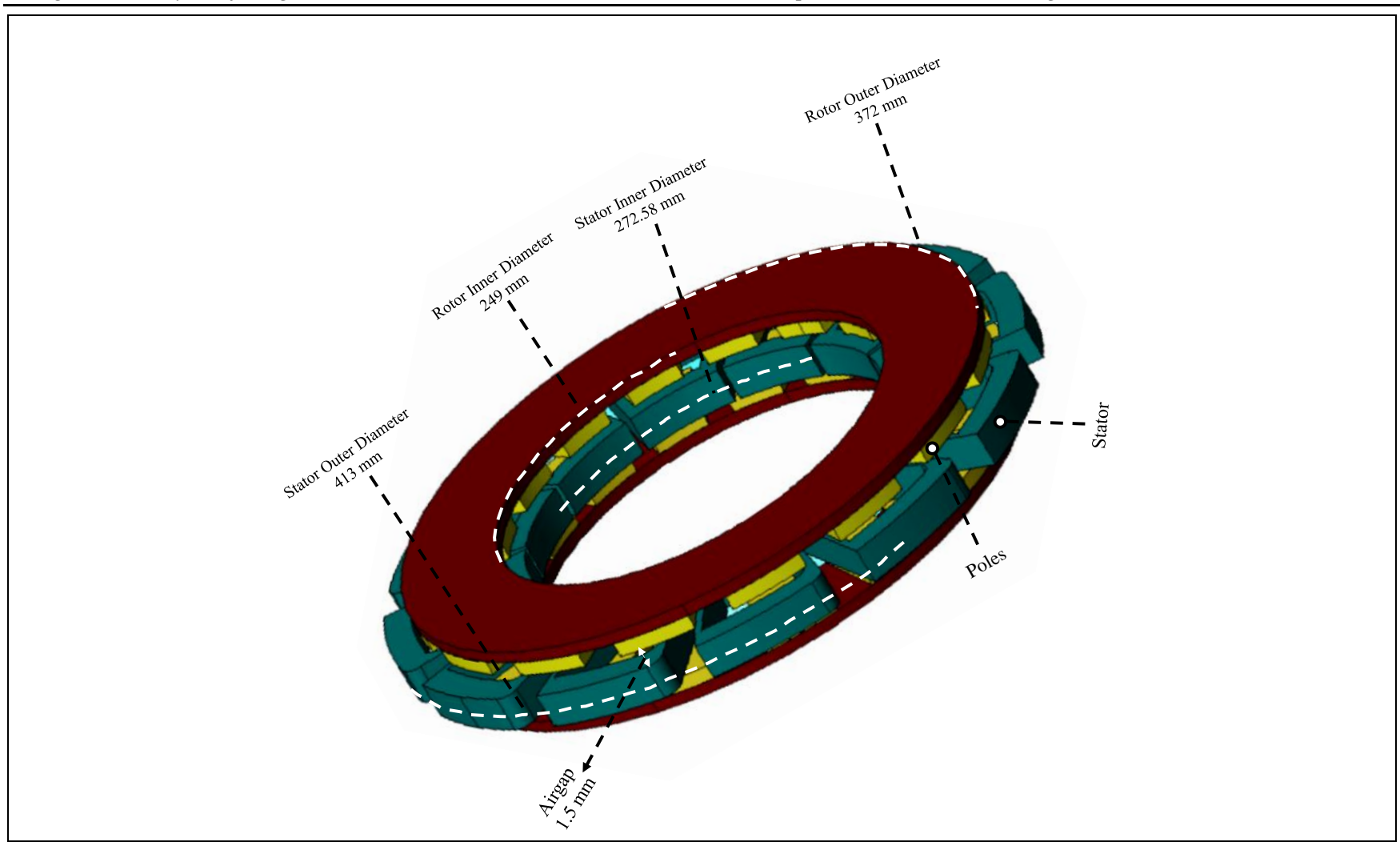

Figure 5: Single Stack AFPM Machine Designed Model

\section{ANALYSIS AND RESULTS}

In this paper, first, the machines are designed with the help of SolidWorks software and after that, the files of SolidWorks are imported into JMAG for analysis. So, FEM is adopted to perform and analyze the single stack AFPM machine with and without air gap at a synchronous speed of 375 RPM. Results obtained include output power, back EMF, coil flux linkage, and magnetic flux density. Figure (6) and Figure (7) show the output power of a single stack AFPM machine with gap and without gap respectively. The output power is $1469.64 \mathrm{~W}$ which is almost equal to $1.5 \mathrm{~kW}$. In addition to this, input power is $3 \mathrm{~kW}$, so the efficiency of a single stack AFPM machine according to projectdesigned parameters is about $50 \%$. The output power is in steady-state condition with minute fluctuations which are tolerable. The running time of the simulation is 0.02 seconds which is equivalent to one power cycle as shown in Figure (6). Meanwhile, the output power of the machine without an air gap is almost the same as it is in the case of the rotor with an air gap but there are certain fluctuations observed at the output which are not tolerable and the issue of power quality is notified in this scenario. This is shown in Figure (7).

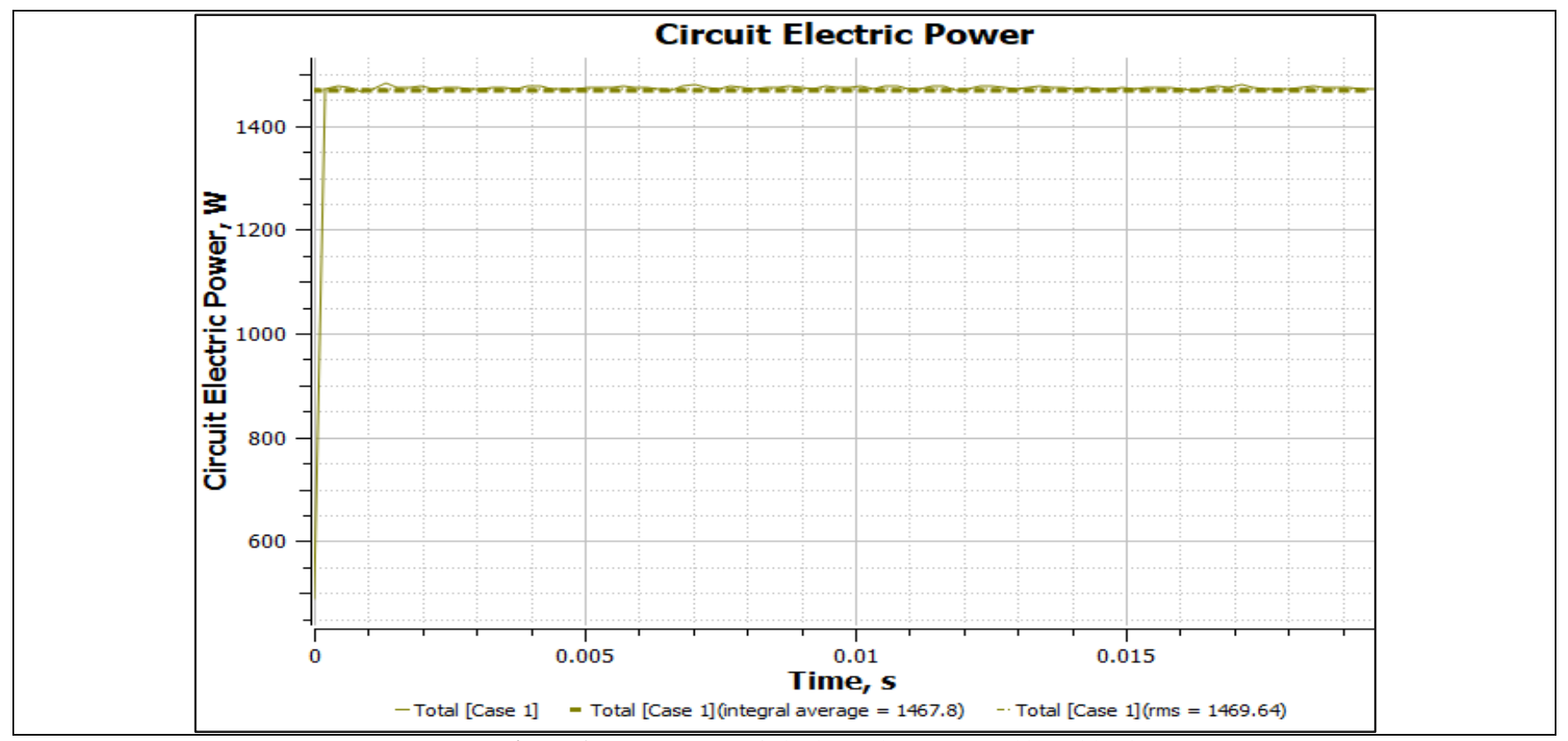

Figure 6: Output Power of Single Stack AFPM Machine with Air Gap 


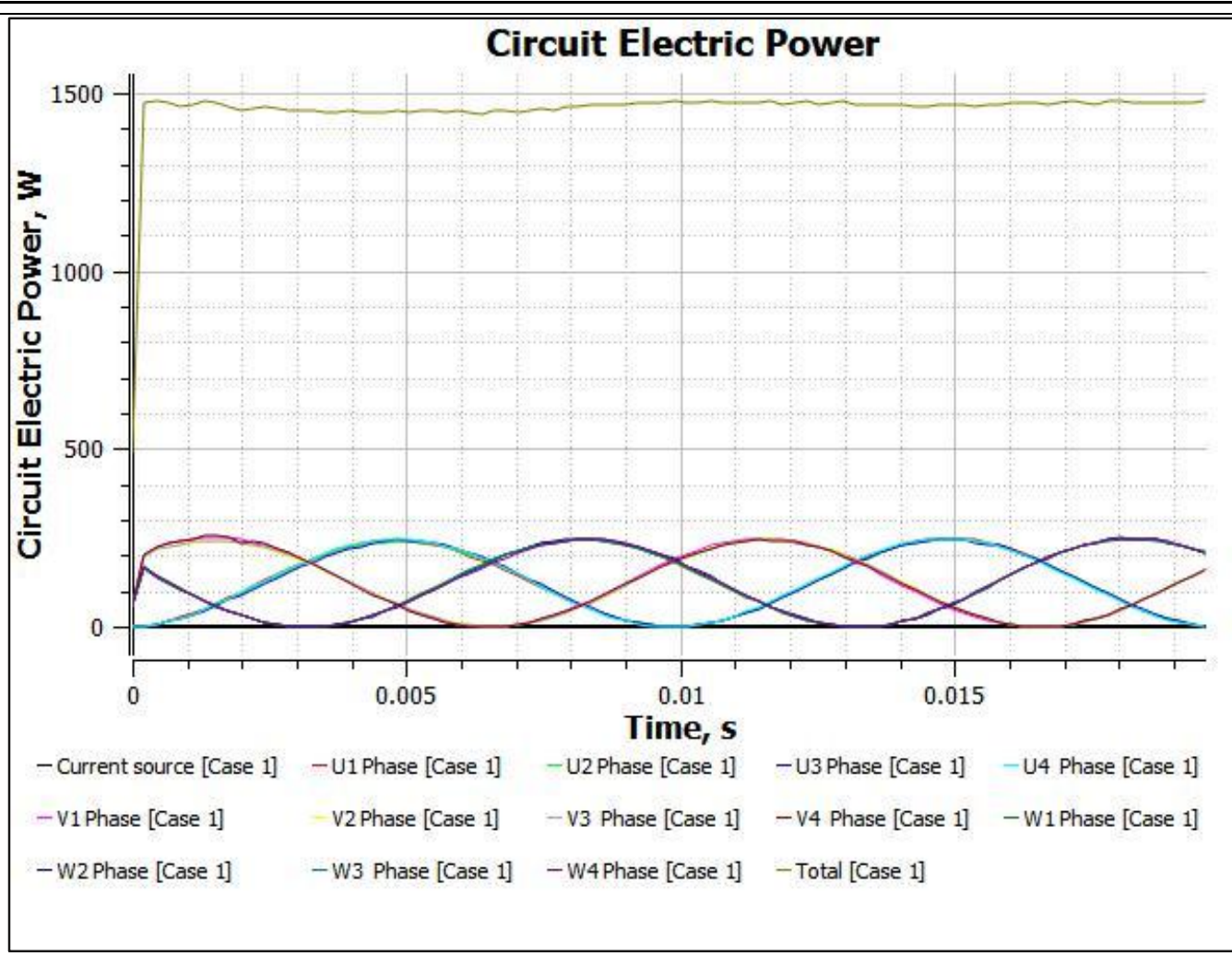

Figure 7: Output Power of Single Stack AFPM Machine without Air Gap

Figure 8 and Figure 9 show the back EMF of single stack AFPM machine with air gap and without air gap respectively. Back EMF is also known as no-load voltage. It is clear from the figure that phases are 120 degrees apart from each other. Black, green and red colors show the Phase-A(U), Phase-B(V), and Phase-C(W) respectively. It is obvious from Figure 8, there is no fluctuation observed at the output voltage hence the machine is generating the three-phase balanced voltages. The peak value is about $140 \mathrm{~V}$ hence RMS Value will be $172 \mathrm{~V}$. The running time of the simulation is 0.02 seconds which is equivalent to one power cycle. The output voltage of machines in both cases will remain the same.

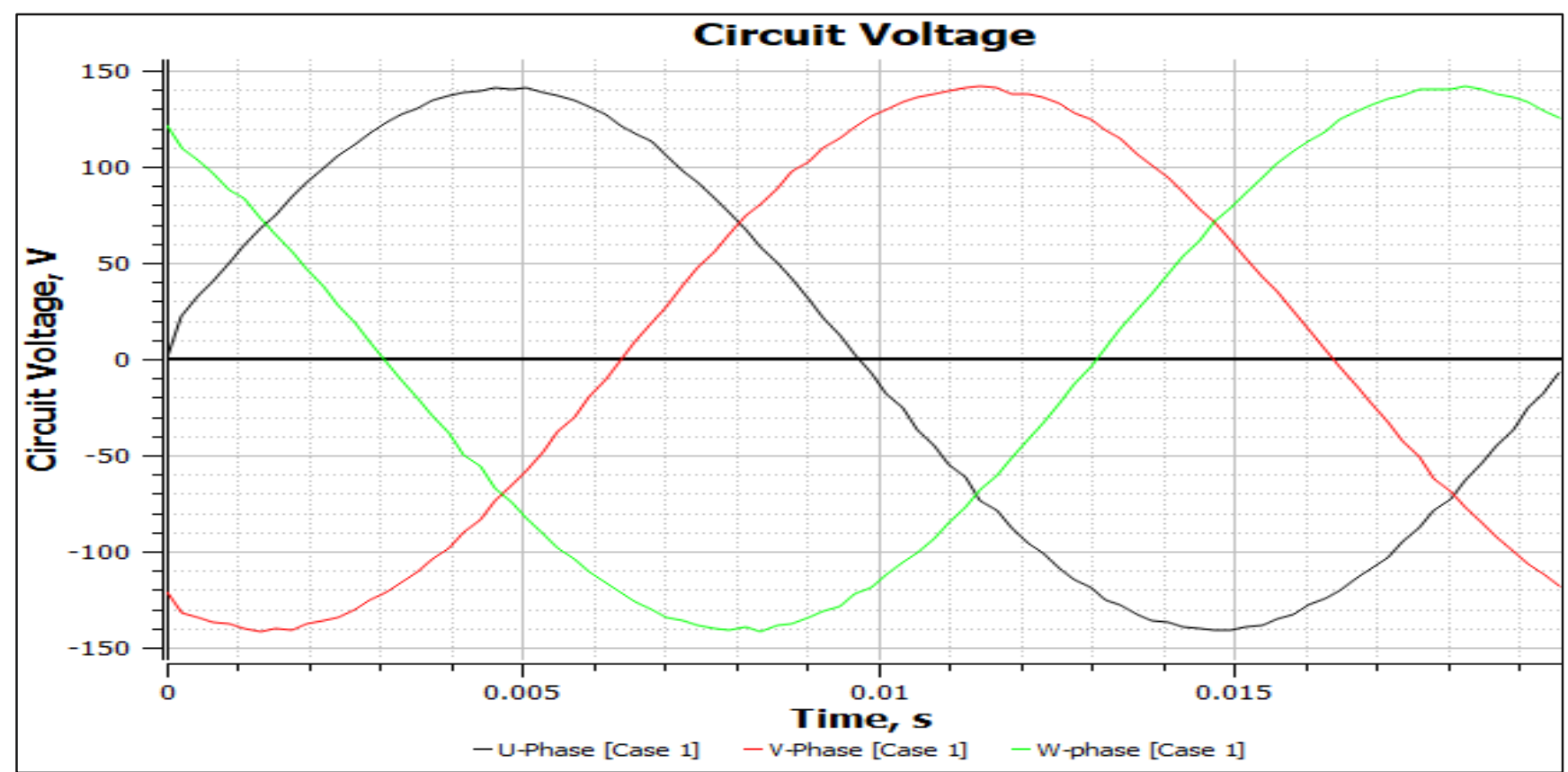

Figure 8: Back EMF of Single Stack AFPM Machine with Air Gap

Figure 10 and Figure 11 shows coil flux linkage of single stack AFPM machine with and without air gap. The peak value of the flux linkage is almost 0.01 Weber. The Flux linkage value is important while selecting magnetic material and should not saturate at peak values. Since three phases of sinusoidal voltage are applied to the stator 
winding the flux developed is also sinusoidal. As threephase balanced voltages are applied the flux developed is also balanced which is producing a smooth rotating field and this is clearly shown in Figure 10. However, due to no air gap between the rotor and magnetic poles, the peak values of the machine start saturating and unbalanced output voltages are analyzed. In addition to this value of magnetic flux also enhances which is about 0.02 weber as shown in Figure11.

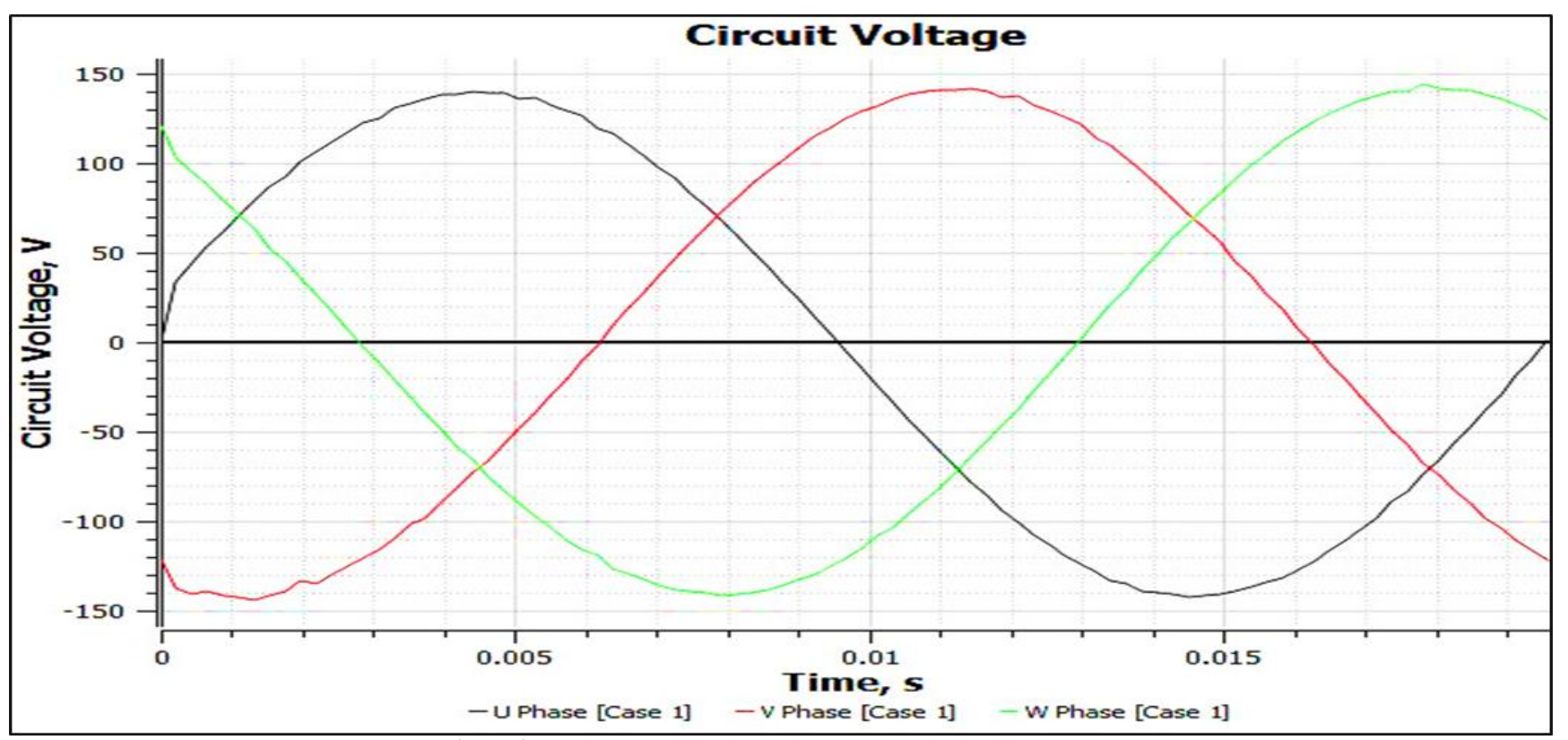

Figure 9: Back EMF of Single Stack AFPM Machine without Air Gap

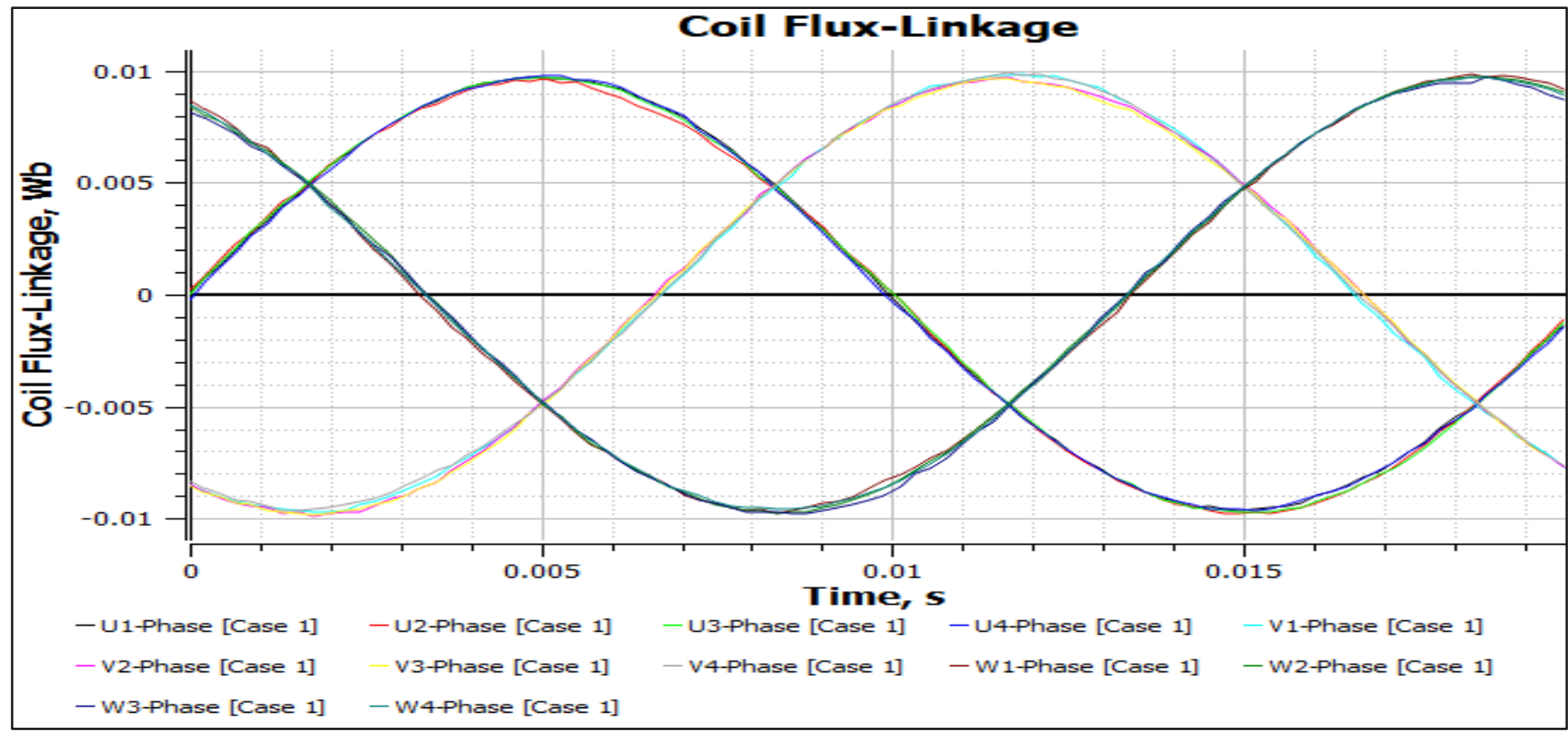

Figure 10: Coil flux Linkage of Single Stack AFPM Machine with Air Gap

Figure 12(a) and Figure 12(b) show the flux density of a single stack AFPM machine with air gap and without air gap in the contour plot. It represents the spectrum of the magnetic flux density at different points. Flux density is maximum at the centre, and it is almost 1.4956 Tesla whereas, flux density decreases and the minimum value analysed is 0.0009 Tesla as shown in Figure 11. Besides, it is inversely proportional to the length so when there is no gap between the rotor and magnetic poles its value enhances and it is about 1.9647 Tesla as shown in Figure 12(b). The step size is kept 19 and 1 for machines with air gap and without air gap in order to observe accuracy correspondingly. So, more accuracy is analysed with respect to spectrum in Figure 12(a) rather than Figure 12(b). The comparative analysis of both machines with distinct parameters has been mentioned in Table 3 .

Table 3: Comparative Analysis of Single Stack AFPM Machine with Air

\begin{tabular}{|l|c|c|}
\hline \multicolumn{1}{|c}{ Parameters } & $\begin{array}{c}\text { Machine with an } \\
\text { Air Gap }\end{array}$ & $\begin{array}{c}\text { Machine without } \\
\text { Air Gap }\end{array}$ \\
\hline Output Power & $1469.64 \mathrm{~W}$ & $1469.4 \mathrm{~W}$ \\
\hline Back EMF & $140 \mathrm{~V}$ & $140 \mathrm{~V}$ \\
\hline Coil Flux Linkage & 0.01 weber & 0.02 weber \\
\hline Flux Density & $1.495 \mathrm{~T}$ & $1.9647 \mathrm{~T}$ \\
\hline Step Size & 19 & 1 \\
\hline
\end{tabular}




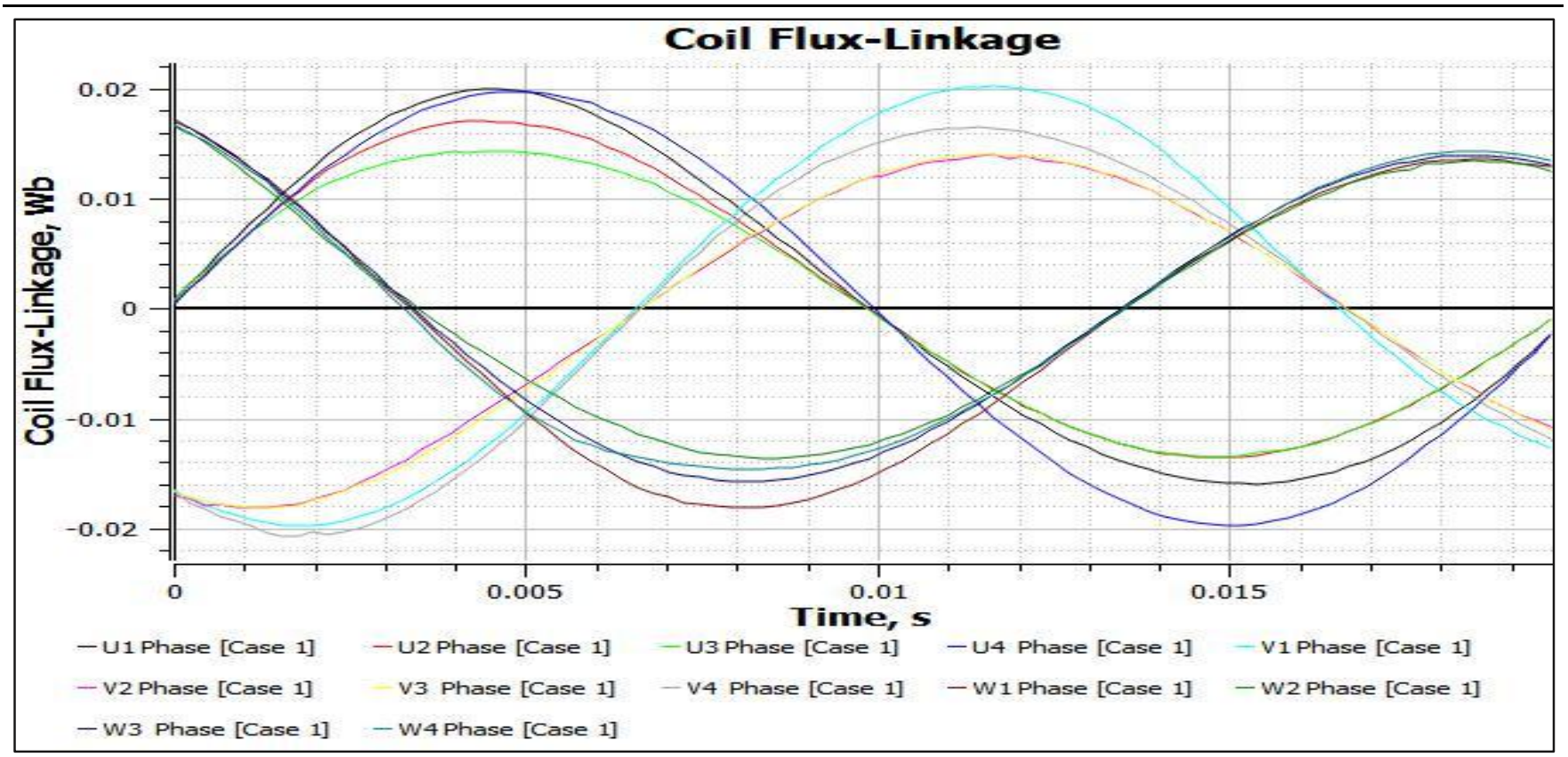

Figure 11: Coil Flux Linkage of Single Stack AFPM Machine without Air Gap

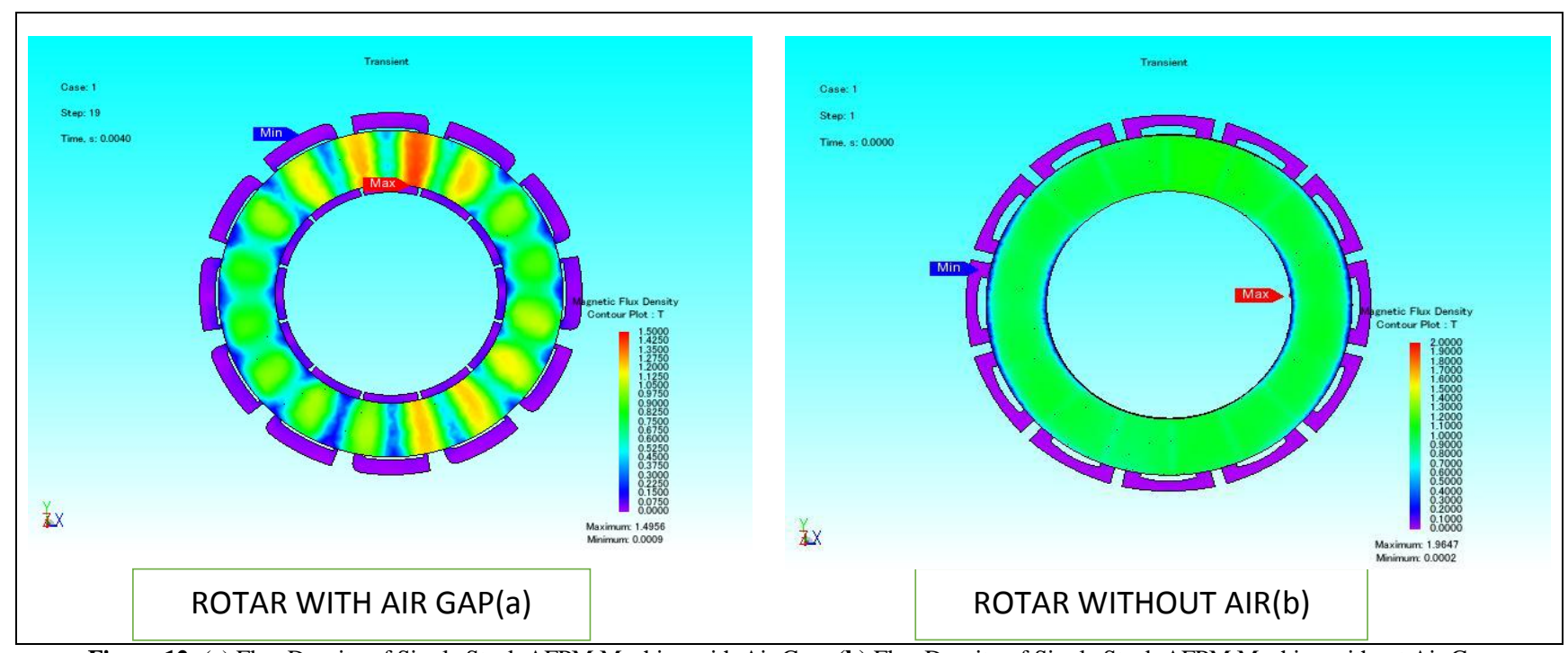

Figure 12: (a) Flux Density of Single Stack AFPM Machine with Air Gap; (b) Flux Density of Single Stack AFPM Machine without Air Gap

\section{CONCLUSION}

In this paper, a study on two machines is carried out which includes single stack machines with two outer rotors and one inner stator with air gap and without air gap. Moreover, the initial parameters considered for the machine with air gap and without air gap are the same and these are electric power, back EMF, coil flux, and magnetic flux density. Apart from this, the first machine is designed into SolidWorks and then files are imported into JMAG designer. From results, first, it was observed that the power of single stack machines with air gap and without air gap is the same, but ripples are analysed in the machine without air gap. Second, the back EMF of both machines is the same, third, the flux was increasing in the machine without air gap, and it was also analysed that power quality is affected due to unbalancing of phases at the output. Finally, the magnetic flux density is more in the machine in which there is no air gap.

\section{Acknowledgement}

This work has been carried out under the guidance of Dr. Sabir Hussain Shah. Along with this, we are also thankful to Electrical Engineering Department, Sukkur IBA University for providing the software facility at their Electrical Machines Research Laboratory.

\section{Author Contributions}

The contributions of all the authors in this research are as follows; Abdul Majeed Shaikh contributed to conceptualization, methodology, review and editing. Umar Abdul Majeed contributed invalidation and formal analysis. Muhammad Fawad Shaikh did investigation and validation. Sheeraz Ahmed contributed to resources, data collection, validation, and data curation. Mohammad Bux facilitated writing and formatting the original draft along with proofreading. 


\section{Conflict of Interest}

All authors do not have any conflict.

\section{Data Availability Statement}

The data of this research study may be shared upon request.

\section{Funding}

The authors do not have received funding for this research study.

\section{References}

[1] Ahmed, A., Shaikh, A. M., Shaikh, M. F., \& Ahmed, S. (2021). Experimental Study of Various Parameters during Speed Control of Three-phase Induction Motor Using GPIC and LabVIEW. Annals of Emerging Technologies in Computing (AETiC), 5(1), 51-62.

[2] Abid, G., Shaikh, S. A., Shaikh, M. F., Rajput, S. H., Majeed, U. A., $\&$ Shaikh, A. M. (2020, January). IoT-based Smart Industrial panel for controlling Three-phase Induction motor. In 2020 3rd International Conference on Computing, Mathematics and Engineering Technologies (iCoMET) (pp. 1-8). IEEE.

[3] Zia, S. (2018). Multiple Colors Making System Using PLC. Sir Syed University Research Journal of Engineering \& Technology, 8(2).

[4] Abdullah, M., \& Naqvi, A. H. (2019). Techno-economic Study for Water Pumping by Solar Power Driven Three Phase Induction Motor. Sir Syed University Research Journal of Engineering \& Technology, 9(1).

[5] Koondhar, M. A., Malak, A. A., Bajwa, M. S., Koondhar, N. A., Jamali, M. I., \& Channa, I. A. (2020). Impact of Load Factor on Distinct Feeders of 132/11 kV Grid Station in Distribution Network. Sir Syed University Research Journal of Engineering \& Technology, 10(02).

[6] Akuru, U. B., and Kamper, M. J. (2015, September). Evaluation of flux switching PM machines for medium-speed wind generator drives. In 2015 IEEE Energy Conversion Congress and Exposition (ECCE) (pp. 1925-1931). IEEE.

[7] Jahns, T. (2017). Getting rare-earth magnets out of EV traction machines: A review of the many approaches being pursued to minimize or eliminate rare-earth magnets from future EV drivetrains. IEEE Electrification Magazine, 5(1), 6-18.

[8] Bouloukza, I., Mordjaoui, M., Kurt, E., Bal, G., Ökmen, C. (2018). Electromagnetic design of new radial flux permanent magnet motor. Journal of Energy Systems; 2(1), 13- 27.

[9] Memon, A. A., Shaikh, M. M., Bukhari, S. S. H., \& Ro, J. S. (2020). Look-up Data Tables-Based Modeling of Switched Reluctance Machine and Experimental Validation of the Static Torque with Statistical Analysis. Journal of Magnetics, 25(2), 233-244.

[10] Bukhari, S. S. H., Sirewal, G. J., Chachar, F. A., \& Ro, J. S. (2020). Dual-inverter-controlled brushless operation of wound rotor synchronous machines based on an open-winding pattern. Energies, 13(9), 2205.

[11] Al-Timimy, A., Giangrande, P., Degano, M., Galea, M., \& Gerada, C. (2017, April). Comparative study of permanent magnetsynchronous and permanent magnet-flux switching machines for high torque to inertia applications. In 2017 IEEE Workshop on Electrical Machines Design, Control and Diagnosis (WEMDCD) (pp. 45-51). IEEE.

[12] Ayub, M., Bukhari, S. S. H., Jawad, G., \& Kwon, B. I. (2019). Brushless wound field synchronous machine with third-harmonic field excitation using a single inverter. Electrical Engineering, 101(1), 165-173.

[13] Ali, Q., Bukhari, S. S. H., \& Atiq, S. (2019). Variable-speed, subharmonically excited BL-WRSM avoiding unbalanced radial force. Electrical Engineering, 101(1), 251-257.

[14] Arshad, S., \& Selvi, V. (2017). 2D electromagnetic design of flux reversal generator for low-speed wind applications using finite element analysis. International Journal of Engineering Technology Science and Research (IJETSR), 4, 149-157.
[15] More, D. S., Kalluru, H., \& Fernandes, B. G. (2008, November). Comparative analysis of Flux Reversal machine and Fractional slot concentrated winding PMSM. In 2008 34th Annual Conference of IEEE Industrial Electronics (pp. 1131-1136). IEEE.

[16] He, Q., \& Wang, Q. (2012, March). Optimal design of low-speed permanent magnet generator for wind turbine application. In 2012 Asia-Pacific Power and Energy Engineering Conference (pp. 1-3). IEEE.

[17] Khan, S., Bukhari, S. S. H., \& Ro, J. S. (2019). Design and analysis of a 4-kW two-stack coreless axial flux permanent magnet synchronous machine for low-speed applications. IEEE Access, 7, 173848-173854.

[18] Chen, Y., Pillay, P., \& Khan, A. (2004, October). PM wind generator comparison of different topologies. In Conference Record of the 2004 IEEE Industry Applications Conference, 2004. 39th IAS Annual Meeting. (Vol. 3, pp. 1405-1412). IEEE.

[19] Faiz, J., Valipour, Z., Shokri-Kojouri, M., \& Khan, M. A. (2016, June). Design of a radial flux permanent magnet wind generator with low coercive force magnets. In 2016 2nd International Conference on Intelligent Energy and Power Systems (IEPS) (pp. 17). IEEE.

[20] Tarımer, İ., \& Ocak, C. (2009). Performance comparison of internal and external rotor structured wind generators mounted from same permanent magnets on the same geometry. Electronics and Electrical Engineering, 92(4), 65-7.

[21] Pop, A. A., Jurca, F., Oprea, C., Chirca, M., Breban, S., \& Radulescu, M. M. (2013, September). Axial-flux vs. radial-flux permanent-magnet synchronous generators for micro-wind turbine application. In 2013 15th European Conference on Power Electronics and Applications (EPE) (pp. 1-10). IEEE.

[22] Syed, Q. A. S., You, Y. M., \& Kwon, B. I. (2012). Design and comparative analysis of single and multi-stack axial flux permanent magnet synchronous generator. International Journal of Applied Electromagnetics and Mechanics, 39(1-4), 865-872.

[23] Lim, J. P., Rho, J. S., Yi, K. P., Seo, J. M., \& Jung, H. K. (2009). Characteristic analysis of a traveling wave ultrasonic motor using an ellipsoidal static contact model. Smart Materials and Structures, 18(11), 115024.

[24] Daghigh, A., Javadi, H., \& Torkaman, H. (2016). Design optimization of direct-coupled ironless axial flux permanent magnet synchronous wind generator with low cost and high annual energy yield. IEEE transactions on magnetics, 52(9), 1-11.

[25] Mbidi, D. N. (2001). Design and evaluation of a $300 \mathrm{~kW}$ double stage axial-flux permanent magnet generator (Doctoral dissertation, Stellenbosch: Stellenbosch University).

[26] Aghili, A., Besmi, M. R., \& Ghadamyari, M. A. (2012, February). A novel structure for axial flux permanent magnet machines with the internal stator. In 2012 3rd Power Electronics and Drive Systems Technology (PEDSTC) (pp. 68-73). IEEE.

[27] Mahmoudi, A., Rahim, N. A., \& Hew, W. P. (2011). Axial-flux permanent-magnet machine modeling, design, simulation, and analysis. Scientific Research and Essays, 6(12), 2525-2549.

[28] Minaz, M. R., \& Çelebi, M. (2017). Design and analysis of a new axial flux coreless PMSG with three rotors and double stators. Results in physics, 7, 183-188. 